\title{
Suppression of Fas Expression and Down-Regulation of Fas Ligand in Highly Aggressive Human Thyroid Carcinoma
}

\author{
Fulvio Basolo, Lisa Fiore, Andrea Baldanzi, Riccardo Giannini, \\ Michela Dell'Omodarme, Gabriella Fontanini, Furio Pacini, Romano Danesi, \\ Paolo Miccoli, and Antonio Toniolo
}

Department of Oncology, Division of Pathology (FB, LF, AB, RG, MD, GF), Division of Pharmacology (RD), Department of Endocrinology (FP), Department of Surgery (PM), University of Pisa, Pisa; and Department of Clinical and Biological Sciences (AT), University of Insubria, Varese, Italy

\begin{abstract}
SUMMARY: The Fas-FasL system seems to mediate thyrocyte death in Hashimoto's thyroiditis. In thyroid cancer, downregulation of $\mathrm{bcl}-2$ seems to alter apoptosis control. We compared the expression of immunoreactive Fas and FasL in normal thyroid with that of tumors ranging from benign to highly aggressive. Fas is essentially not expressed in normal thyrocytes, whereas FasL is expressed in approximately one-third of cases. Expression of both markers is significantly up-regulated in adenoma and in well-differentiated papillary and follicular carcinoma. In contrast, Fas is suppressed and FasL is strongly reduced in the most aggressive histological variants (poorly differentiated and undifferentiated carcinoma). Immunohistochemistry findings have been confirmed by analysis of Fas-FasL mRNA transcripts. In vitro studies showed that the Fas receptor of thyroid tumor cells was functional, because apoptosis was induced by an agonistic Fas antibody. Fas-expressing and Fas-resistant mammary cell lines were used as specificity controls. Together with our previous data inversely relating bcl-2 expression and thyroid tumor grade, the present findings further indicate that apoptotic pathways are altered in thyroid neoplasia. Thus, the Fas-FasL system may represent a marker of tumor aggressiveness. (Lab Invest 2000, 80:1413-1419).
\end{abstract}

$A$ Iterations of negative cell growth control play a key role in cancer pathogenesis and progression (Brown and Wouters, 1999). Fas (APO-1, CD95) is a member of the family of tumor necrosis factor and nerve growth factor surface receptors; its ligand (FasL) belongs to this same group of membrane and secreted proteins (Nagata, 1998). The Fas-FasL system is involved in the induction of apoptosis in cells of the immune system as well as in a variety of fetal and adult tissues (Yu et al, 1999). Expression of FasL in certain immunologically privileged sites suggested that FasL may play a role in maintaining immune privilege, a view that has been challenged by experimental evidence (Chen et al, 1998; Kang et al, 1998). Although comprehension of the physiological role of the Fas-FasL system is incomplete, apoptosis caused by the activation of this system seems to play a key role in the pathogenesis of cancer and virus infections (Kondo et al, 1997; Brown and Wouters, 1999). Some studies indicate that Fas and its ligand are involved in endocrine autoimmunity, with particular regard to the pan-

Received April 27, 2000.

This work was supported by the Italian Association for Cancer Research (AIRC, Milan, Italy) and Istituto Superiore di Sanità (ISS-AIDS, Rome; grant \# 9405-12).

Address reprint requests to: Dr. Fulvio Basolo, Department of Oncology, Division of Pathology, University of Pisa, 57, Via Roma, 56126 Pisa, Italy. Fax: 39050992 706; E-mail:f.basolo@do.med.unipi.it creas and thyroid (Giordano et al, 1997; Kurts et al, 1999). Some data indicate that Fas or its ligand, or both, are expressed in normal thyrocytes (Kawakami et al, 1996; Fiedler et al, 1998; Arscott et al, 1999). Thyroid tumors represent the most common form of endocrine neoplasia and their incidence is increasing, possibly in relation to environmental factors (Zitzelsberger et al, 1999). Little is known about alterations of apoptosis control in thyroid cancer, except for reports showing that alterations of bcl-2 protein expression, an inhibitor of apoptotic pathways, are detected in aggressive forms of thyroid cancer (Basolo et al, 1997, 1999). We studied the expression of immunoreactive Fas-FasL in neoplastic thyroid lesions ranging from benign to highly aggressive. For comparison, FasFasL expression was evaluated in normal adult tissue. Results have been compared with the analysis of mRNA transcripts in fresh tissues derived from the same patients and investigated by immunohistochemistry. We show here that Fas and FasL are weakly expressed in normal thyroid follicular cells and that the expression of these markers is significantly upregulated in benign lesions and in well-differentiated thyroid carcinoma. In contrast, expression of both mediators is strongly reduced in the most aggressive histological variants. Studies of cultured thyroid follicular cells (TFC) showed that the Fas receptor expressed on these cells was functional, because an 
agonistic Fas antibody seemed to trigger apoptosis of neoplastic thyrocytes.

\section{Results}

\section{Fas and FasL Expression in Normal Thyroid Tissue and} Neoplastic Lesions

Only 2 of 73 (3\%) samples of normal tissue were stained by Fas antibody, thus normal tissue was considered Fas-negative (Table 1). Among neoplastic lesions, significant Fas expression was detected in benign tumors (12 of 39 adenomas, 31\%) and in papillary thyroid carcinoma (PTC; 34 of 48, 77\%), which is one of the least aggressive histotypes of thyroid carcinoma (Fig. 1, a and b). Three of $5(60 \%)$ nodal PTC metastases were also positive. Similarly, 8 of $12(67 \%)$ follicular thyroid carcinomas were positive. Notably, none of 38 cases of the most aggressive forms of thyroid cancer (poorly differentiated carcinoma [PDC], undifferentiated carcinoma [UC], and node metastasis from UC) were Fas-positive. In UC, rare nests of Fas-positive well-differentiated carcinoma cells were interspersed amid Fas-negative undifferentiated tissue (Fig. 1c). These results were confirmed by RT-PCR analysis of Fas transcripts in PTC and collateral normal tissue from 20 patients that had been characterized by immunostaining. Faint bands corresponding to Fas mRNA transcript were detected in four samples of normal tissue, whereas clear bands were produced by amplification of 14 of 20 (70\%) PTC. Representative results are shown in Figure 2. Immunoreactivity for cytoplasmic FasL protein was investigated in 59 samples of normal thyroid tissue and in 134 neoplastic lesion samples. Results are reported in Table 2. Fas-L expression was seen in 19 of $59(32 \%)$ normal samples. Immunoreactivity was significantly increased in adenomas (28 of $38,74 \%$ ), in PTC and its metastatic lesions (46 of $49,94 \%$ ), as well as in follicular thyroid carcinomas (8 of 12, 67\%). FasL positivity was well represented in PDC (14 of 19, 74\%), but strongly reduced in UC and its metastatic lesions (5 of 16, 31\%; Fig. 1, d and e). These results were confirmed by RT-PCR analysis of FasL transcripts (Fig. 2).

\section{Fas and FasL in Thyroid Cell Cultures}

By RT-PCR analysis of mRNA transcripts, primary cultures obtained from four patients with PTC as well as the FB-2 cell line (derived from a papillary tumor), were found to be Fas-positive and FasL-negative. In contrast, the FB-1 and FB-3 cell lines derived from UC expressed both Fas and FasL mRNA (data not shown). As shown in Figure 3, the three thyroid cells were positive by immunoblotting for a protein band of 43 $\mathrm{kDa}$, corresponding to Fas; the signal was equivalent to that detected in the extract of Jurkat cells used as positive control (Hirata et al, 1998). Expression of Fas at the protein level was confirmed by immunostaining of cultured cells: slight cytoplasmic and marked membrane positivity was observed in more than $80 \%$ of cells (data not shown).

\section{Induction of Apoptosis In Vitro}

The functional activity of Fas expressed in thyroid carcinoma cell lines (FB-1, FB-2, and FB-3) was analyzed by measuring the viability of cultured cells after treatment with an agonistic Fas antibody. As measured by both MTT [3-(4, 5-dimethylthiazol-2-yl)2,5-diphenyl tetrazolium bromide] assay and propidium iodide (PI) staining, treatment caused a significant reduction of cell viability (and a corresponding increase in the percentage of apoptotic nuclei) in Fas-positive thyroid lines and in the T47D breast cancer line used as a Fas-sensitive control (Table 3). In contrast, viability of two Fas-resistant mammary cell lines (MCF-7 and MDA-MB-231) was not affected by the agonistic antibody, thus demonstrating the specificity of the phenomenon.

\section{Discussion}

Histopathologic and experimental studies have shown that normal TFC are Fas-negative and FasL-positive (Giordano et al, 1997), that Fas expression is upregulated on PTC (Arscott et al, 1999), and that cultured thyrocytes express a functional Fas receptor, because apoptotic death is triggered by cross-linking agents (Bretz et al, 1999). Fas-activated apoptosis seems to be potentiated by pretreatment with combi-

Table 1. Fas Protein Expression in Normal and Neoplastic Thyroid Tissue

\begin{tabular}{lcrrr}
\hline \multicolumn{1}{c}{ Histotype } & & \multicolumn{3}{c}{ Immunoreactivity $^{a}$} \\
\cline { 3 - 5 } & No. of cases & Negative & Low & Strong \\
\hline Normal tissue & 73 & $71(97 \%)$ & $2(3 \%)$ & - \\
Adenoma & 39 & $27(69 \%)$ & $9(23 \%)$ & $3(8 \%)$ \\
PTC & 48 & $11(23 \%)$ & $11(23 \%)$ & $23(54 \%)$ \\
PTC (lymph node metastases) & 5 & $2(40 \%)$ & $2(40 \%)$ & $1(20 \%)$ \\
FTC & 12 & $4(33 \%)$ & $3(25 \%)$ & $5(42 \%)$ \\
PDC & 19 & $19(100 \%)$ & - & - \\
UC & 16 & $16(100 \%)$ & - & - \\
UC (lymph node metastases) & 3 & $3(100 \%)$ & - & - \\
\hline
\end{tabular}

${ }^{a}$ Immunoreactivity represents proportion of positive cells: negative, $<5 \%$; low, 5-50\%; strong, $>50 \%$. 

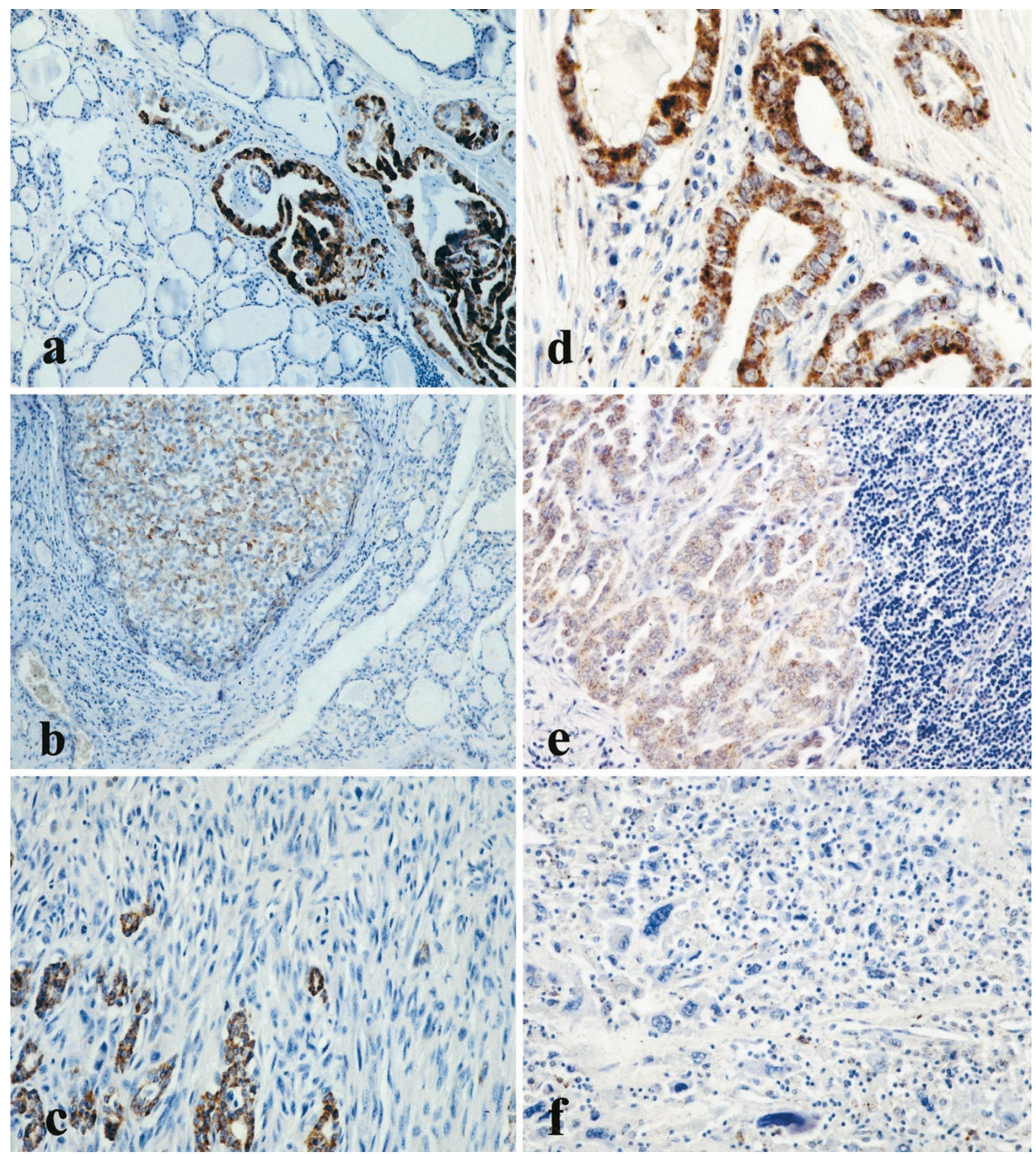

\section{Figure 1.}

a to c, Immunohistochemical staining for Fas of formalin-fixed, paraffin-embedded thyroid carcinoma; Harris hematoxylin counterstaining. Well-differentiated papillary thyroid carcinoma (PTC) shows a strong immunoreactivity for Fas. Normal thyroid tissue is negative (a); a weak immunoreactivity is present in this case of follicular variant of PTC (b); undifferentiated thyroid carcinoma fails to show any immunoreactivity for Fas, whereas interspersed nests of well-differentiated carcinoma are Fas-positive (c). $\mathrm{d}$ to $\mathrm{f}$, Immunoreactivity for FasL in well-differentiated thyroid carcinoma, metastases from PTC, and undifferentiated thyroid carcinoma. Well-differentiated thyroid carcinoma (d) and its metastatic lesions (e) show a clear cytoplasmic immunoreactivity, whereas undifferentiated carcinoma (f) is negative. Original magnifications, a, b, and f, $\times 120 ; c, d$, and e, $\times 240$.

nations of inflammatory cytokines (ie, interferon- $\gamma$, tumor necrosis factor- $\alpha$, and interleukin- $1 \beta$; Bretz et al, 1999) and this may play a role in both neoplastic and autoimmune thyroid disease. Our histopathologic results show that normal TFC fail to express Fas, whereas FasL was detected in approximately onethird of cases. Analysis of neoplastic lesions showed that more than $70 \%$ of adenomas and welldifferentiated thyroid carcinomas (papillary and follicular histotypes) express Fas and FasL. In contrast, UC were negative for Fas and positive for FasL expression in approximately one-third of cases. Because the specificity of certain antibodies used for FasL immunochemistry has been questioned (Smith et al, 1998), 
$\begin{array}{lllllllllll}M & 1 \mathrm{~N} & 1 \mathrm{~T} & 2 \mathrm{~N} & 2 \mathrm{~T} & 3 \mathrm{~N} & 3 \mathrm{~T} & 4 \mathrm{~N} & 4 \mathrm{~T} & \mathrm{M}\end{array}$

Fas
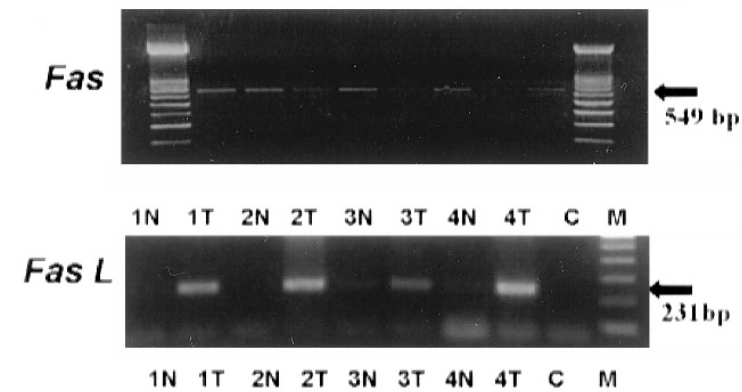

GAPDH

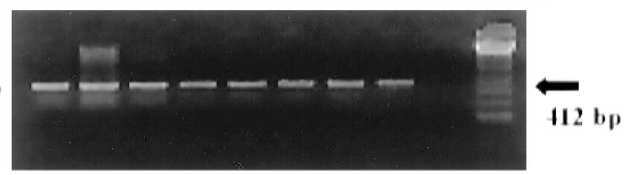

\section{Figure 2.}

RT-PCR amplification of total RNA extracted from normal and neoplastic thyroid tissue. PCR primers specific for Fas, FasL, and glyceraldehyde-3phosphate dehydrogenase $(G A P D H)$ were used. $M$, molecular size markers. Representative samples of the following: normal tissue, $1 N, 2 N, 3 N, 4 N$; well-differentiated thyroid carcinoma, 1T, 2T, 3T, 4T. Ethidium bromidestained agarose gel.

analysis of Fas and FasL mRNA transcripts was performed in both thyroid tissue and cultured TFC. Immunostaining results were confirmed by RT-PCR.

The biological significance of simultaneous expression of Fas and FasL in the same cell is not clear. Three possible roles for the Fas-FasL system have been proposed in tumor biology: (a) an immune escape mechanism in which secreted FasL would engage the Fas receptor of tumor infiltrating lymphocytes triggering apoptosis (Hahne et al, 1996; Mitsiades et al, 1999), (b) an inhibitory pathway in which FasL may directly kill Fas-expressing tumor cells (Nagata, 1998), and (c) a Fas-driven stimulation of tumor cell growth (Shinohara et al, 2000). Resistance to Fas-triggered death may be caused by highlevel expression of anti-apoptotic genes of the $b c l-2$ family or production of Fas pathways inhibitors (eg, soluble Fas, intracellular regulators; Bretz et al, 1999).

Recent data suggest that the autocrine/paracrine Fas-FasL interaction predominates in Hashimoto's thyroiditis, in which it seems to mediate thyrocyte destruction (Stassi et al, 1999). Experimental studies indicate that secreted FasL may also play a role in inflammation through the activation of interleukin-1 $\beta$ (Miwa et al, 1998) and by attracting infiltrating leukocytes (Allison et al, 1997). In this context, it should be considered that the apoptotic or inflammatory activity of the Fas-FasL system depends on at least two factors: the level of Fas expression on target cells and the relative amounts of cytoplasmic, membranebound, and secreted FasL (Miwa et al, 1998).

The present study shows that high levels of both Fas and FasL are expressed in benign and welldifferentiated histotypes of thyroid neoplasia, whereas PDC and UC are Fas-negative and show only limited expression of FasL. It should be noted that in culture, thyroid cells obtained from PTC and even UC express detectable levels of Fas (protein and transcripts). We showed that the Fas receptor expressed by both cell types was functional, because its stimulation with an agonistic Fas antibody induced cell death (but failed to trigger apoptosis in Fas-resistant cell lines). However, our methods did not allow us to ascertain whether thyroid cells did release soluble Fas or FasL. This could be an important issue for understanding thyroid tumorigenesis, because of the regulatory activity of both molecules on Fas-dependent pathways (eg, the effects on bystander thyrocytes and infiltrating lymphocytes; Chen et al, 1998).

Although Fas-FasL expression in benign tumors may be interpreted as a physiological mechanism controlling tumor progression (Nagata, 1998), it is worth noting that Fas expression was completely abolished in highly aggressive thyroid tumors, as already reported in esophageal squamous carcinoma and in melanoma (Gratas et al, 1998; Chappell et al 1999). Down-regulation of Fas is often interpreted as an immune escape mechanism hindering both autocrine/paracrine and T-lymphocyte-mediated apoptotic pathways (O'Connel et al, 1998).

Leukocyte infiltration is not particularly relevant in most thyroid cancers, suggesting that the main significance of Fas-FasL expression in benign and welldifferentiated thyroid neoplasia is not that of stimulating inflammation. Our previous studies on thyroid carcinoma indicate that the proportion of apoptotic cells is significantly increased in aggressive neoplasia and that levels of the bcl-2 protein are inversely related to the apoptotic index (Basolo et al, 1997). Taken together, these observations indicate that apoptotic pathways are altered in malignant thyroid lesions and that the Fas-FasL system may represent a marker for assessing tumor aggressiveness.

\section{Materials and Methods}

\section{Patients}

The investigated thyroid tumors were derived from a series of patients seen at the Institute of Endocrinology of the University of Pisa (the largest Italian center for thyroid disease) who received primary surgical treatment at the Department of Surgery of the same University. Initial treatment was total or near-total thyroidectomy in all patients, regardless of the histotype. Histological diagnosis of tumors was made at the Department of Oncology of the same University according to Sobrinho-Simoes (1995). Malignant thyroid tumors from 95 patients included 48 PTC, 12 follicular thyroid carcinomas, 19 PDC, 16 UC, and 9 lymph node metastatic lesions (6 from PTC and 3 from UC). Adenomas were collected from 39 patients (micro- and macrofollicular histotype). Normal thyroid tissue from the unaffected lobe of each patient was studied as control.

\section{Cultures of Thyroid Follicular Cells}

Sterile samples of thyroid tissue were obtained at surgery and subjected to mechanic and collagenase dissociation to obtain TFC which were cultured as 
Table 2. FasL Protein Expression in Normal and Neoplastic Thyroid Tissue

\begin{tabular}{lcccc}
\hline \multirow{2}{*}{ Histotype } & \multicolumn{3}{c}{ Immunoreactivity $^{a}$} \\
\cline { 3 - 5 } & No. of cases & Negative & Low & Strong \\
\hline Normal tissue & 59 & $40(68 \%)$ & $16(27 \%)$ & $3(5 \%)$ \\
Adenoma & 38 & $10(26 \%)$ & $11(29 \%)$ & $17(45 \%)$ \\
PTC & 43 & $3(7 \%)$ & $13(30 \%)$ & $27(63 \%)$ \\
PTC (lymph node metastases) & 6 & - & $2(33 \%)$ & $4(67 \%)$ \\
FTC & 12 & $4(33 \%)$ & $6(50 \%)$ & $2(17 \%)$ \\
PDC & 19 & $6(30 \%)$ & $7(35 \%)$ & $7(35 \%)$ \\
UC & 13 & $9(69 \%)$ & $4(31 \%)$ & - \\
UC (lymph node metastases) & 3 & $2(67 \%)$ & - & $1(33 \%)$ \\
\hline
\end{tabular}

${ }^{a}$ Immunoreactivity represents proportion of positive cells: negative, $<5 \%$; low, 5-50\%; strong, $>50 \%$.

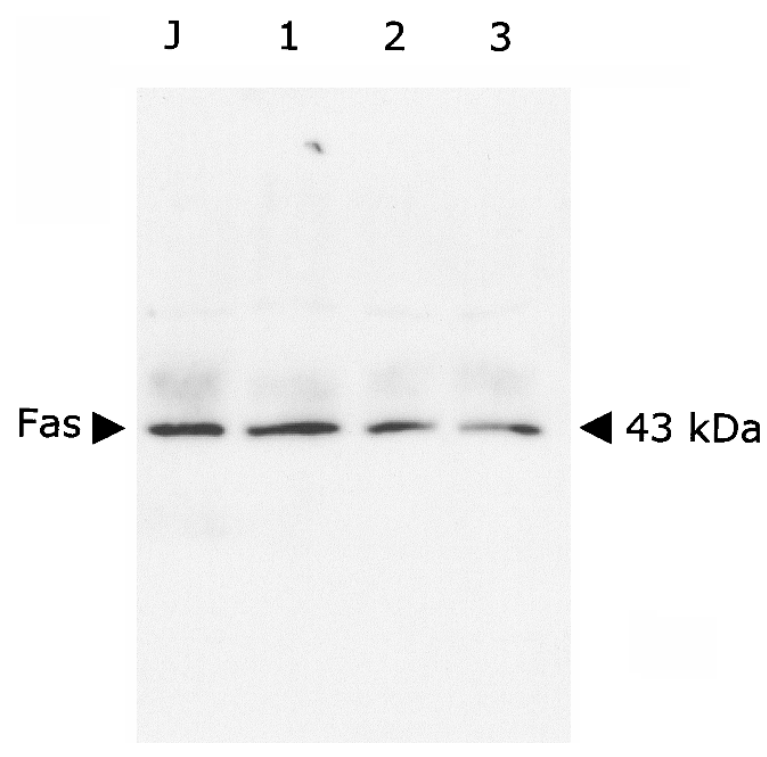

Figure 3.

Immunoblot detection of p43 Fas protein in whole-cell lysates of Jurkat cells (positive control, lane J) and thyroid cell lines FB-1, FB-2, and FB-3 (lanes 1 to 3).

reported (Basolo et al, 1998) in Dulbecco's modified Eagle's medium containing $10 \%$ fetal bovine serum (low endotoxin type). Primary cultures were used for experiments between 30 and 50 days after plating, that is, at a time when contaminant non-epithelial cells were $<5 \%$ as judged by morphology and immunocytochemistry. Primary cultures and the following TFC lines were used: FB-1 (derived from UC; Fiore et al, 1997), FB-3 (from UC; F Basolo, unpublished data), FB-2 (from PTC; F Basolo, unpublished data), and FB-2 carrying the T-large antigen of SV40 virus (tumorigenic, F Basolo, unpublished data). Cultured cells were characterized by immunocytochemistry as reported (Basolo et al, 1998). Chemicals, media, and serum were from Sigma Chemical (St. Louis, MO).

\section{Immunohistochemistry}

Tissue samples were formalin fixed, paraffin embedded, and stained with hematoxylin and eosin. For immunohistochemistry, paraffin sections (3-5 $\mu \mathrm{m})$ were dewaxed in xylene, dehydrated through graded alcohols, and blocked with 5\% non-immune mouse or rabbit serum in PBS with $0.05 \%$ sodium azide for 5 minutes. Mouse monoclonal antibody against AP01/ Fas (clone 11G10; Novocastra, Newcastle, UK) or rabbit polyclonal antibody that maps at the amino terminus of human FasL (Q-20; Santa Cruz Biochemical, Santa Cruz, CA) were added at 1:1,000 dilution for 15 minutes. After incubation with biotinylated antimouse or anti-rabbit secondary antibody for 15 minutes followed by streptavidin-biotin complex for 15 minutes (Catalyzed Signal Amplification System; DAKO, Copenhagen, Denmark), sections were developed for 5 minutes with $0.05 \%$ 3,3'-diaminobenzidine tetrahydrochloride, $0.01 \%$ hydrogen peroxide in $0.05 \mathrm{M}$ Tris- $\mathrm{HCl}$ buffer $\mathrm{pH} 7.6$, counterstained with hematoxylin, dehydrated, and mounted. FB-1, FB-2, FB-3 carcinoma cell monolayers and Fas-positive Jurkat cells (used as controls) were grown in chamber slides. After fixation in $4 \%$ buffered paraformaldehyde, semiconfluent monolayers were stained with Fas and FasL antibody as reported above.

\section{Immunohistochemical Evaluation}

Each section was examined independently by two pathologists ( $\mathrm{AB}$ and $\mathrm{FB}$ ) for the surface expression of Fas and for cytoplasmic FasL staining. Depending on the proportion of positive cells, immunostaining was classified as negative $(<5 \%)$, low $(5-50 \%)$, or strong (>50\%). Statistical analysis was performed with PC software (Statistica; StatSoft, Tulsa, OK).

\section{Immunoblot Detection of Fas}

The human T cell Jurkat leukemia cell line was used as a positive control for immunoblot analysis of Fas (Hirata et al, 1998) and grown in complete RPMI 1640. Jurkat and FB-1, FB-2, and FB-3 thyroid cell lines in exponential growth phase were washed twice with ice-cold PBS, solubilized in lysis buffer (1\% Triton X-100, 10 mm Tris, pH 7.5, 1 mm EDTA, 0.3 M sucrose, $1 \mathrm{~mm}$ phenylmethylsulfonyl fluoride, and $5 \mu \mathrm{g} / \mathrm{ml}$ each of pepstatin A, antipain, and aprotinin) for 30 minutes at $4^{\circ} \mathrm{C}$, and centrifuged for 30 minutes at 16,000 rpm. Equal protein amounts $(30 \mu \mathrm{g})$ of the detergentsoluble fraction were boiled in sample buffer $(50 \mathrm{~mm}$ 
Table 3. Apoptotic Response of Cell Lines to IgM Anti-Fas Antibody: MTT Assay and Percentage of Apoptotic Nuclei by PI Staining

\begin{tabular}{lccccccc}
\hline & \multicolumn{3}{c}{ MTT assay $\left(\mathrm{A}_{590}\right)^{a}$} & & \multicolumn{3}{c}{$\%$ apoptotic nuclei $^{b}$} \\
\cline { 2 - 3 } \multicolumn{1}{c}{ Cultures } & Medium & Anti-human Fas & $p^{c}$ & & Medium & Anti-human Fas & $p^{c}$ \\
\hline Thyroid cell lines & & & & & & & \\
FB-1 & $0.421 \pm 0.07$ & $0.245 \pm 0.01$ & $<0.05$ & & $3.6 \pm 1.3$ & $11.4 \pm 3.7$ & $<0.01$ \\
FB-2 & $0.324 \pm 0.06$ & $0.140 \pm 0.01$ & $<0.01$ & & $3.1 \pm 1.5$ & $9.6 \pm 2.8$ & $<0.01$ \\
FB-3 & $0.625 \pm 0.09$ & $0.217 \pm 0.01$ & $<0.01$ & & $6.4 \pm 2.7$ & $31.9 \pm 4.6$ & $<0.01$ \\
FB2+SV40 & $0.646 \pm 0.05$ & $0.327 \pm 0.03$ & $<0.01$ & & $5.6 \pm 1.4$ & $27.8 \pm 5.2$ & $<0.01$ \\
Mammary cell lines & & & & & & & \\
T47D & $0.738 \pm 0.09$ & $0.416 \pm 0.10$ & $<0.01$ & & $4.3 \pm 2.8$ & $34.5 \pm 6.7$ & $<0.01$ \\
MCF-7 & $0.651 \pm 0.16$ & $0.692 \pm 0.14$ & NS & & $6.6 \pm 3.4$ & $9.7 \pm 4.4$ & NS \\
MDA-MB-231 & $0.426 \pm 0.13$ & $0.394 \pm 0.06$ & NS & & $3.5 \pm 2.0$ & $7.2 \pm 3.3$ & NS \\
\hline
\end{tabular}

${ }^{a}$ MTT assay: see text for details. Data are expressed as absorbance at $590 \mathrm{~nm}$ (mean \pm SC of 3-4 wells). Fas-positive (T47D) and Fas-resistant (MCF-7 and MDA-MB-231) mammary cell lines were used as controls.

${ }^{b}$ Cells in chamber slides were fixed with paraformaldehyde and stained with propidium iodide. Apoptotic nuclei were counted with an epifluorescence microscope at least 500 cells/well were counted (mean \pm SC).

${ }^{c}$ Significance levels calculated by unpaired Student's $t$ test; NS, not significant.

Tris, $\mathrm{pH} 6.8,2 \%$ SDS, $100 \mathrm{~mm}$ dithiothreitol, $10 \%$ glycerol, and $0.025 \%$ bromophenol blue), separated on $12.5 \%$ SDS-polyacrylamide mini-gel (BioRad, Richmond, CA), and transferred to polyvinylidene difluoride membranes (Millipore Corporation, Bedford, MA) by a Multiphor II NovaBlot cell (Pharmacia, Piscataway, $\mathrm{NJ}$ ). Blots were probed with affinity-purified mouse anti-Fas IgM (Upstate Biotechnology, Lake Placid, NY) at $2 \mu \mathrm{g} / \mathrm{ml}$ in $20 \mathrm{~mm}$ Tris $\mathrm{pH} 7.6,137 \mathrm{~mm}$ $\mathrm{NaCl}, 0.1 \%$ Tween-20 and $5 \%$ non-fat dry milk. Signals were visualized by anti-mouse HRP-linked secondary antibody with enhanced chemiluminescence detection system (ECL; Amersham Corp., Arlington Heights, IL).

\section{RT-PCR for Fas and FasL}

Total RNA was extracted from 18 samples of fresh normal and neoplastic tissue using a kit from Qiagen (Valencia, CA). cDNA was synthesized from $2.5 \mu \mathrm{g}$ of template RNA using a cDNA synthesis kit for RT-PCR based on avian myeloblastosis virus reverse transcriptase (AMV/RT) (Boehringer-Mannheim, Monza, Italy). Published primer sequences were as follows: Fas transcript (Mitra et al, 1996; forward 5'-CAA GTG ACT GAC ATC AAC TCC and reverse 5'-CCT TGG TTT TCC TTT CTG TGC), FasL transcript (O'Connel et al, 1998; forward 5'-CTG GGG ATG TTT GAG CTC TTC-3' and reverse 5'-CTT CAC TCC AGA AAG CAG GAC- $3^{\prime}$ ). Products from Fas and FasL mRNA were 549-bp and 231-bp, respectively. As a control, GAPDH mRNA was amplified with published primers; a 412-bp product was obtained. PCR molecular biology reagents were from Perkin-Elmer Applied Biosystems (Monza, Italy). Each reaction was carried out in a $50-\mu$ volume, including $10 \times$ reaction buffer, $\mathrm{MgCl}_{2}$, dNTP, 20 pmol primers, and 2.5 unit of Taq polymerase. Samples were denatured at $97^{\circ} \mathrm{C}$ for 2 minutes before 28 amplification cycles, which were followed by final extension at $72^{\circ} \mathrm{C}$ for 5 minutes. DNA products were analyzed on $2 \%$ agarose gel using ethidium bromide and UV illumination for detection of fragments.

\section{Apoptosis Assay}

The functional activity of Fas in mediating apoptosis induced by an agonistic IgM anti-Fas antibody (clone $\mathrm{CH}-11$; Upstate Biotechnology) was analyzed in thyroid cell lines and, for control, in a Fas-positive breast cancer cell line (T47D) and in two Fas-resistant mammary cell lines (MCF-7 and MDA-MB-231; Yu et al, 1999). Briefly, $5 \times 10^{3}$ cells seeded in 96-well tissue culture plates were allowed to grow in complete medium for 2 days. After washing with warm PBS, cultures were incubated for 12 hours at $37^{\circ} \mathrm{C}$ in serum-free medium with or without the anti-Fas antibody $(100 \mathrm{ng} / \mathrm{ml})$. Cell culture viability was assessed by the MTT method as reported (Basolo et al, 1998). After overnight incubation, the MTT solution was removed and the blue formazan product formed in live cells by oxidation was solubilized and absorbance was measured at $590 \mathrm{~nm}$ with a microplate reader. In addition, the apoptotic response was evaluated by counting the numbers of apoptotic cell nuclei by $\mathrm{PI}$ staining (McGahon et al, 1995). Cells in chamber slides were fixed with $2 \%$ paraformaldehyde in PBS for 10 minutes at $4^{\circ} \mathrm{C}$, treated with PI solution for 20 minutes at room temperature, then examined with an epifluorescence microscope. At least 500 cells per well were counted; experiments were made in triplicate. The apoptotic state was further evaluated by differential uptake of acridine orange and ethidium bromide $\left(5 \times 10^{4}\right.$ cells in $25 \mu$ l of PBS stained with 1 $\mu \mathrm{l}$ of $100 \mu \mathrm{g} / \mathrm{ml}$ acridine orange and $100 \mu \mathrm{g} / \mathrm{ml}$ ethidium bromide). Observed through wide-band FITC filters, early apoptotic cells are characterized by condensed or fragmented bright green chromatin, late apoptotic cells by condensed or fragmented bright orange chromatin. 


\section{References}

Allison J, Georgiou HM, Strasser A, and Vaux DL (1997). Transgenic expression of CD95 ligand on islet $\beta$ cells induces granulocytes infiltration but does not confer immune privilege upon islet allografts. Proc Natl Acad Sci USA 94:3943-3947.

Arscott PL, Stokes T, Myc A, Giordano TJ, Thompson NW, and Baker JR (1999). Fas (CD95) expression is up-regulated on papillary thyroid carcinoma. J Clin Endocrinol Metab 84:4246-4252.

Basolo F, Fiore L, Fusco A, Giannini R, Albini A, Merlo GR, Fontanini G, Conaldi PG, and Toniolo A (1999). Potentiation of the malignant phenotype of the undifferentiated ARO cell line by insertion of the bcl-2 gene. Int J Cancer 81:956-962.

Basolo F, Fiore L, Pollina L, Fontanini G, Conaldi PG, and Toniolo A (1998). Reduced expression of interleukin 6 in undifferentiated thyroid carcinoma. Clin Cancer Res 4:381387.

Basolo F, Pollina L, Fontanini G, Fiore L, Pacini F, and Baldanzi A (1997). Apoptosis and proliferation in thyroid carcinoma: Correlation with bcl-2 and p53 protein expression. Br J Cancer 75:537-541.

Bretz JD, Arscott PL, Myc A, and Baker JR (1999). Inflammatory cytokine regulation of Fas-mediated apoptosis in thyroid follicular cells. J Biol Chem 274:25433-25438.

Brown JM and Wouters BG (1999). Apoptosis, p53, and tumor cell sensitivity to anticancer agents. Cancer Res 59: 1391-1399.

Chappell DB, Zaks TZ, Rosenberg SA, and Restifo NP (1999). Human melanoma cells do not express Fas (Apo-1/CD95) ligand. Cancer Res 59:59-62.

Chen J-J, Sun Y, and Nabel GJ (1998). Regulation of the proinflammatory effects of Fas ligand (CD95L). Science 282: 1714-1717.

Fiedler P, Schaetzlein CE, and Eibel H (1998). Constitutive expression of FasL in thyrocytes. Science 279:2015.

Fiore L, Pollina L, Fontanini G, Casalone R, Berlingeri M, Giannini R, Pacini F, Miccoli P, Toniolo A, Fusco A, and Basolo $F$ (1997). Cytokine production by a new undifferentiated human thyroid carcinoma cell line, FB-1. J Clin Endocrinol Metab 82:4094-4100.

Giordano C, Stassi G, De Maria R, Todaro M, Richiusa P, Papoff G, Ruberti G, Bagnasco M, Testi R, and Galluzzo A (1997). Potential involvement of Fas and its ligand in the pathogenesis of Hashimoto's thyroiditis. Science 275:960963.

Gratas C, Tohma Y, Barnas C, Taniere P, Hainaut P, and Ohgaki H (1998). Up-regulation of Fas (APO-1/CD95) ligand and down-regulation of Fas expression in human esophageal cancer. Cancer Res 58:2057-2062.

Hahne M, Rimoldi D, Schröter M, Romero P, Schreier M, French LE, Schneider P, Bornand T, Fontana A, Lienard D, Cerottini J-C, and Tschopp J (1996). Melanoma cell expression of Fas (Apo-1/CD95) ligand: Implications for tumor immune escape. Science 274:1363-1366.

Hirata H, Takahashi A, Kobayashi S, Yonehara S, Sawai H, Okazaki T, Yamamoto K, and Sasada M (1998). Caspases are activated in a branched protease cascade and control distinct downstream processes in Fas-induced apoptosis. J Exp Med 187:587-600.
Kang SM, Lin Z, Ascher NL, and Stock PG (1998). Fas ligand expression on islets as well as multiple cell lines results in accelerated neutrophilic rejection. Transplant Proc 30:538.

Kawakami A, Eguchi K, Matsouka N, Tsuboi M, Kawabe Y, Ishikawa N, Ito K, and Nagataki S (1996). Thyroid-stimulating hormone inhibits Fas antigen-mediated apoptosis of human TFC in vitro. Endocrinology 137:3163-3169.

Kondo T, Suda T, Fukuyama $\mathrm{H}$, Adachi $\mathrm{M}$, and Nagata $\mathrm{S}$ (1997). Essential roles of the Fas ligand in the development of hepatitis. Nat Med 3:409-413.

Kurts C, Carbone FR, Krummel MF, Koch KM, Miller JF, and Heath WR (1999). Signalling through CD30 protects against autoimmune diabetes mediated by CD8 T cells. Nature 398:341-344.

McGahon AJ, Martin SJ, Bissonnette RP, Mahboubi A, Shi Y, Mogil RJ, Nishioka WK, and Green DR (1995). The end of the (cell) line: Methods for the study of apoptosis in vitro. Methods Cell Biol 46:153-185.

Mitra D, Steiner M, Lynch DH, Staiano-Coico L, and Laurence J (1996). HIV-1 upregulates Fas ligand expression in $\mathrm{CD} 4+\mathrm{T}$ cells in vitro and in vivo: Association with Fasmediated apoptosis and modulation by aurintricarboxylic acid. Immunology 87:581-585.

Mitsiades N, Poulaki V, Mastorakos G, Tseleni-Balfouta ST, Kotoula V, Koutras DA, and Tsokos M (1999). Fas ligand expression in thyroid carcinoma: A potential mechanism of immune evasion. J Clin Endocrinol Metab 84:2924-2932.

Miwa K, Asano M, Horai R, Iwakura Y, Nagata S, and Suda T (1998). Caspase 1-independent IL-1 beta release and inflammation induced by the apoptosis inducer Fas ligand. Nat Med 4:1287-1292.

Nagata S (1998). Fas-induced apoptosis. Intern Med 37:179_ 181.

O'Connel J, Bennett MW, O'Sullivan GC, Roche D, Kelly J, Collins JK, and Shanahan F (1998). Fas ligand expression in primary colon adenocarcinomas: Evidence that the Fas counterattack is a prevalent mechanism of immune evasion in human colon cancer. J Pathol 186:240-246.

Shinohara H, Yagita H, Ikawa Y, and Oyaizu N (2000). Fas drives cell cycle progression in glioma cells via extracellular signalregulated kinase activation. Cancer Res 60:1766-1772.

Smith D, Sieg S, and Kaplan D (1998). Technical note: Aberrant detection of cell surface Fas ligand with antipeptide antibodies. J Immunol 160:4159-4160.

Sobrinho-Simoes M (1995). Tumors of thyroid: A brief overview with emphasis on the most controversial issues. Curr Diagn Pathol 2:15-22.

Stassi G, Todaro M, Bucchieri F, Stopacciaro A, Farina F, Zummo G, Testi R, and De Maria R (1999). Fas/Fas ligand-driven T cell apoptosis as a consequence of ineffective thyroid immunoprivilege in Hashimoto's thyroiditis. J Immunol 162:263-267.

Yu W, Israel K, Liao QY, Aldaz CM, Sanders BG, and Kline K (1999). Vitamin E succinate (VES) induces Fas sensitivity in human breast cancer cells: Role for Mr 43:000 Fas in VEStriggered apoptosis. Cancer Res 59:953-961.

Zitzelsberger H, Lehmann L, Hieber L, Weier HU, Janish C, Fung J, Negele T, Spelsberg F, Lengfelder E, Demidchik EP, Salassidis K, Keller AM, Werner M, and Bauchinger M (1999). Cytogenetic changes in radiation-induced tumours of the thyroid. Cancer Res 59:135-140. 